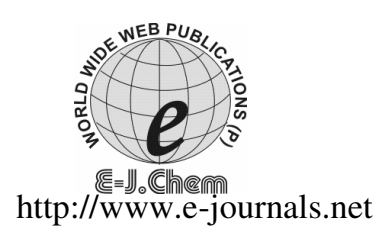

ISSN: 0973-4945; CODEN ECJHAO

E-Journal of Chemistry

2011, 8(2), 917-923

\title{
Efficient Removal of Ce(III) and Eu(III) Ions from Aqueous Solutions by Local Clay -A Radiotracer Study
}

\author{
SOM SHANKAR DUBEY*, BATTULA SREENIVASA RAO, \\ B.S.A. ANDREWS and B.VENKATA KIRAN \\ Department of Chemistry, GITAM Institute of Technology \\ GITAM University, Visakhapatnam-530045, India \\ somshankarbhu@yahoo.co.in
}

Received 17 June 2010; Accepted 15 August 2010

\begin{abstract}
Radiotracer technique has been used to study the removal behavior of $\mathrm{Ce}(\mathrm{III})$ and $\mathrm{Eu}(\mathrm{III})$ ions from aqueous solutions by local clay. Adsorptive concentration $\left(10^{-4}-10^{-6} \mathrm{~mol} \mathrm{dm}^{-3}\right), \mathrm{pH}(\mathrm{ca} 2.0-9.0)$ and temperature (303-333 K) were examined for assessing optimal conditions for removal of these ions. The adsorption phenomenon was highly dependent on the amount of the adsorbent concentrations. The uptake of ions, which fitted well for Freundlich isotherm, increased with increase in the temperature and no significant desorption took place in the studied temperature range. The energy of adsorption process for the both cations indicates that the adsorption phenomenon is of chemisorption type. The rate kinetics of the adsorption followed the first order rate kinetics.
\end{abstract}

Keywords: $\mathrm{Ce}(\mathrm{III}), \mathrm{Eu}(\mathrm{III})$, Clay, Adsorption, Freundlich isotherm, Desorption.

\section{Introduction}

Sorption of radionuclide on natural solids strongly affects the behavior and transport of radionuclide in the environment and complicates their description by mathematical models. Therefore, the sorption has been extensively studied and modeled. Most of the studies dealt with rather simple systems (minerals and solutions) where the sorption can be better interpreted and described. However, real environmental systems are usually complex and the data and knowledge obtained with simple systems cannot be easily used for environmental conditions. Description of sorption on complex natural solids, solely on the basis of known properties of their components, is very difficult, due to complicated mutual interaction of the components, surface coating and similar effects. A more passable way is probably to take such a complex solid as a whole, to characterize it and to develop a suitable method for describing its sorption properties for a given radionuclide ${ }^{1}$. Cerium and europium, being a 
very toxic heavy element, affects the environment adversely and due to this reason, it is very important from environmental pollution and management point of view. Due to their toxicity to human beings, they must be removed from effluent water for clean environment ${ }^{2-4}$.

During the last few decades a large number of metal oxides have been explored for their use in adsorption and for various separations of analytical and radiochemical importance ${ }^{5-8}$. The interest in these materials has grown mainly due to their extra stability towards ionizing radiations and higher temperatures in comparison to their organic counterparts ${ }^{9-11}$. The adsorption process has been found to be useful and popular due to its low maintenance costs, high efficiency and ease of operation. Adsorption of toxic metal ions on soil ${ }^{12-14}$, silica gel ${ }^{15}$ and activated carbon ${ }^{16-17}$ has been described under various related parameters. The effect of various parameters such as concentration, temperature had been examined. The adsorption isotherms during the process have also been discussed and thermodynamic parameters deduced to help in understanding the uptake process.

\section{Experimental}

Cerium(III) and Europium(III) as its sulphate salt was used and stock solution $\left(1.0 \mathrm{~mol} \mathrm{dm}^{-3}\right)$ of metal ion was prepared in double distilled water. The solution was further standardized via the standard method of Flaschka ${ }^{18}$ and then diluted to obtain desired experimental concentrations $\left(10^{-3}-10^{-6} \mathrm{~mol} \mathrm{dm}{ }^{-3}\right)$. The radioactive cerium $\left({ }^{141} \mathrm{Ce}, \mathrm{t}_{1 / 2}=43 \mathrm{~d}\right)$ as its respective sulphate in dilute $\mathrm{H}_{2} \mathrm{SO}_{4}\left(\mathrm{ca} 166.5 \times 10^{6} \mathrm{~Bq}\right)$ and Europium $\left({ }^{148} \mathrm{Eu}, \mathrm{t}_{1 / 2}=54.5 \mathrm{~d}\right)$ was obtained from the Board of Radiation and Isotope Technology (BRIT), Mumbai (India). A very small amount of this radionuclide was used to label the adsorptive solutions to obtain a measurable radioactivity of minute aliquots of withdrawn samples from bulk.

The sorption experiments were performed by stirring, at regular intervals and equilibrating $0.1000 \mathrm{~g}$ of clay with $10.0 \mathrm{~cm}^{3}$ of labeled adsorptive solution. The equilibrated solution was centrifuged for phase separation and then supernatant solution was analyzed for its $\beta$-activity measurements using an end-window GM-counter (Nucleonix, Hyderabad, India). Radio activities of some samples were also checked for their $\gamma$-activity using a Multi Channel Analyzer (Nucleonix, Hyderabad, India). Procedures for estimation of the amount adsorbed and evaluation of other parameters were identical to those given earlier ${ }^{19}$.

\section{Results and Discussion}

\section{Effect of shaking time}

The shaking time ranging from 10 minutes to 48 hours was employed for achieving the equilibrium (Figure 1). More than $99 \%$ of $\mathrm{Eu}(\mathrm{III})$ and $95 \%$ of $\mathrm{Ce}(\mathrm{III})$ was adsorbed after 10 minutes of shanking. The uptake of $\mathrm{Ce}(\mathrm{III})$ was a slow process and it took 16 hours for sorption of more than $99 \% \mathrm{Ce}(\mathrm{III})$. It is apparent that in the beginning the sorption was achieved by ionexchange followed by precipitation of hydrolyzed species slowly, but in case of Eu(III) the precipitation of $\mathrm{Eu}(\mathrm{OH})_{3}$ was rapid and bypassed the formation of chain of these species. For comparison $1 \mathrm{~h}$ shaking time was selected in the both cases for further experiments.

\section{Effect of adsorbent concentration}

The adsorption of both cerium and europium was studied as function of adsorbent concentration from $10 \mathrm{~g} \mathrm{dm}^{-3}$ to $100 \mathrm{~g} \mathrm{dm}^{-3}$. The result is plotted in Figure 2. In case of cerium, $K_{d}$ increased with adsorbent concentration, while in case of europium, $K_{d}$ first increased and then showed a slight decline. This was due to complete and early removal of $\mathrm{Eu}(\mathrm{III})$ ions by lesser weight of soil. 


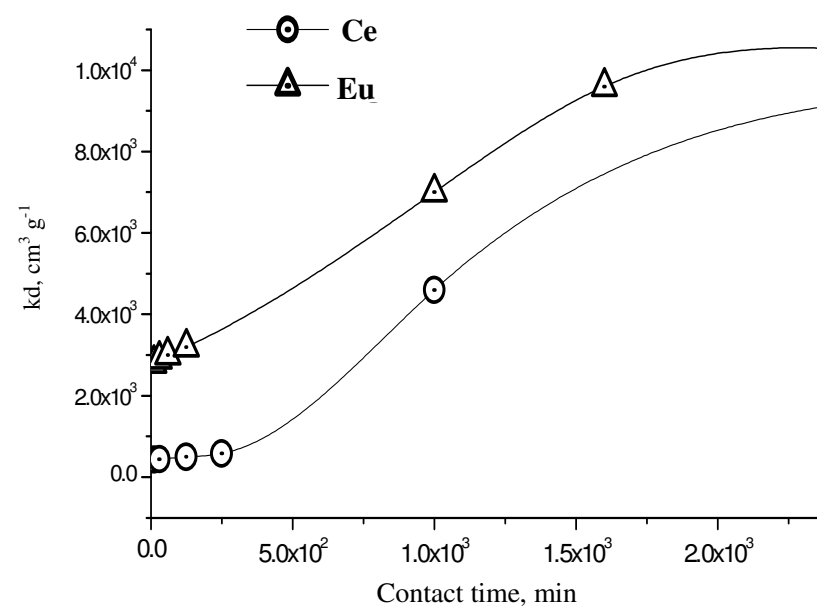

Figure 1. Effect of shaking time on the sorption of $\mathrm{Ce}$ and $\mathrm{Eu}$

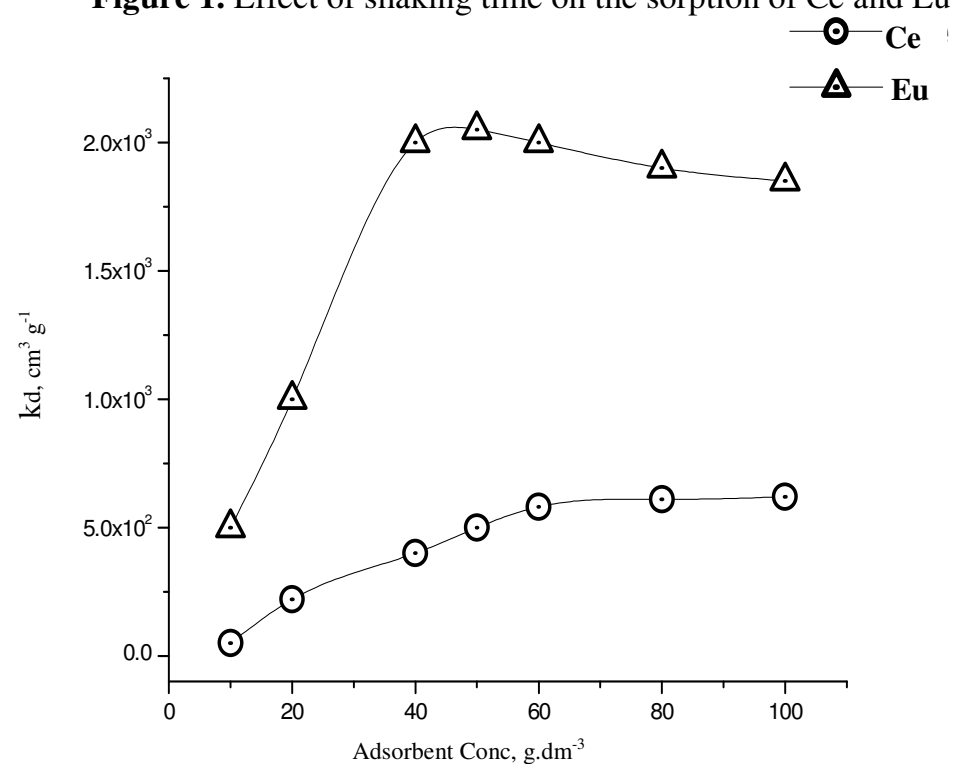

Figure 2. Variation of $\mathrm{K}_{\mathrm{d}}$ of $\mathrm{Ce}$ and Eu with adsorbent concentration

\section{Effect of metal ion concentration}

Concentration effect for the adsorption of $\mathrm{Ce}(\mathrm{III})$ and $\mathrm{Eu}(\mathrm{III})$ on Clay was carried out by varying the adsorptive concentrations at $303 \mathrm{~K}$ and results of the uptake of $\mathrm{Ce}$ (III) and $\mathrm{Eu}$ (III) ions are shown in Figure 3. It is observed that initially a fast uptake of metal ions occurred, which became slower with the lapse of time and an apparent equilibria between the two phases achieved within $c a 10 \mathrm{~min}$ (Ce-Clay and Eu-Clay) of contact time. No further uptake was observed even after $48 \mathrm{~h}$ of contact. Moreover, the smooth and continuous curves leading to saturation for the uptake of the ions over clay infer about the adsorption of metal ions occurring in a single step and not accompanied by any complexity. For Ce(III) the concentration was varied between $3.37 \times 10^{-6}$ to $3.33 \times 10^{-4} \mathrm{~mol} \mathrm{dm}^{-3}$ and for Eu(III) it was varied from $3.59 \times 10^{-6}$ to $3.33 \times 10^{-3} \mathrm{~mol} \mathrm{dm}^{-3}$. This increase in the adsorption is explicable on the basis of the fact that a relatively smaller number of adsorptive species would be available at higher dilution for deposition on an equal number of surface sites of adsorbents ${ }^{20}$. 


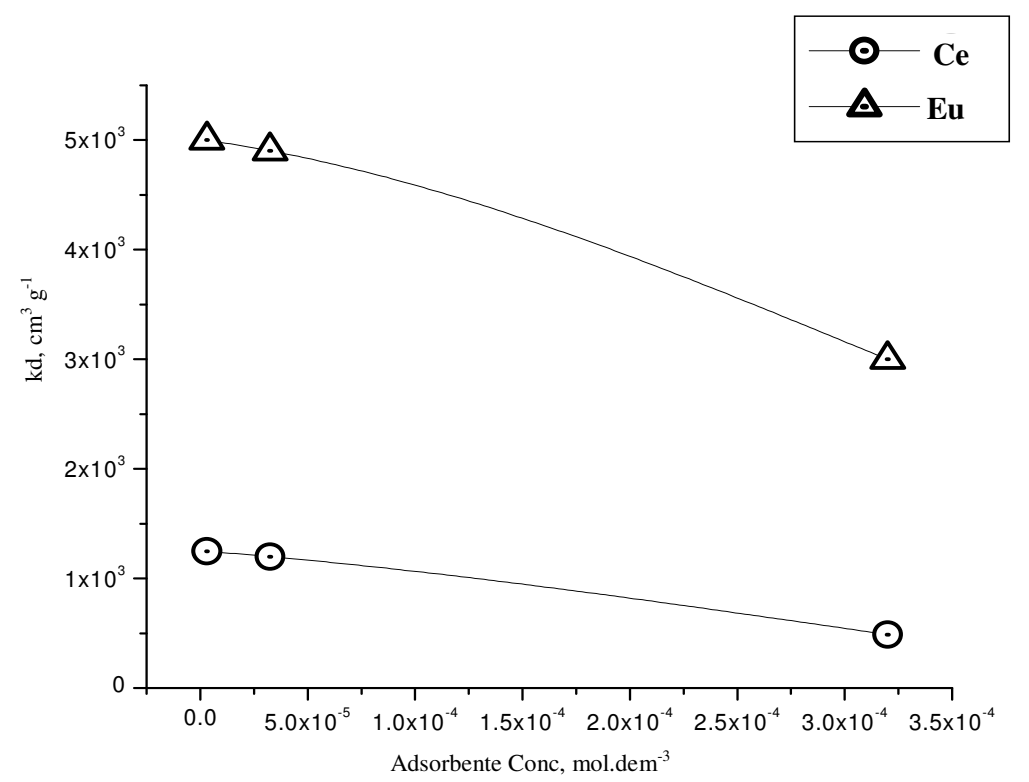

Figure 3. Variation of $\mathrm{K}_{\mathrm{d}}$ with change in adsorbate concentration

\section{Equilibrium modeling}

The concentration dependence data were further utilized in equilibrium modeling of the removal process by using the Freundlich and Langmuir equations. It has been observed that the concentration data fitted well by Freundlich equation (1) rather than the Langmuir equation.

$$
\log a_{e}=\frac{1}{n} \log C_{e}+\log K
$$

Here $a_{e}$ and $C_{e}$ are the amounts adsorbed $\left(\mathrm{mol} \mathrm{g}^{-1}\right)$ at equilibrium and equilibrium bulk concentration $\left(\mathrm{mol} \mathrm{dm}{ }^{-3}\right)$ respectively and $1 / n$ and $K$ are the Freundlich constants which correspond to adsorption intensity and adsorption capacity, respectively. In order to find out these constants a plot has been drawn between $\log a_{e} v s . \log C_{e}$ and straight lines were found for both the systems. These linear plots confirm about the monolayer coverage of ions at the surface of both adsorbents ${ }^{21}$. The value of $1 / n$ and $K$ were 0.953 and $2.81 \times 10^{-2} \mathrm{~mol} \mathrm{~g}^{-1}$ (for Ce-Clay) and 0.842 and $4.46 \times 10^{-2} \mathrm{~mol} \mathrm{~g}^{-1}$ (for Eu-Clay) system, respectively. The fractional values of $1 / n(0<1 / n<1)$ obtained for both the systems are considered to be due to the heterogeneous surface structure of adsorbents with an exponential distribution of surface active sites ${ }^{20}$. The higher numerical values of $K$ for both the systems again confirm the significant affinity of ions for clay.

\section{Effect of temperature}

The effect of solution temperature varying from 303 to $333 \mathrm{~K}$ in steps of $10 \mathrm{~K}$ on adsorption of ions clay has been investigated; the initial concentration of ions being kept at $1.0 \times 10^{-5}$ mol dm ${ }^{-3}$ at $\mathrm{pH} 7.52$ (for Ce-Clay and Eu-Clay) systems. The increase in adsorption of metal ions may be either due to acceleration of slow adsorption steps or due to creation of some new active sites ${ }^{22}$ or to transport against a concentration gradient, and/or diffusion controlled transport across the energy barrier. A kinetic study for the uptake of ions over clays has also been worked out, which follows the first order rate law obeying Lagergren equation:

$$
\log \left(a_{e}-a_{t}\right)=\log a_{e}-k_{1} . t / 2.303
$$


Where $a_{e}$ and $a_{t}$ are the amounts adsorbed at equilibrium and at contact time intervals $t$ and $k_{1}$ is the adsorption rate constant. The values of adsorption rate constants at different temperatures have been estimated from the slopes of straight lines obtained from $\log \left(a_{e}-a_{t}\right)$ $v s$. time and the values are listed in Table 1 and 2 . These values for both systems increase with the increase in temperature, which is in conformity to expectations as adsorption increases with the increase in temperature for non-physical type adsorption.

Table 1. Thermodynamic parameter for adsorption of Ce(III) ions on local clay

\begin{tabular}{|c|c|c|c|c|}
\hline $\begin{array}{c}\text { Temperature, } \\
\mathrm{K} \\
\end{array}$ & $\begin{array}{c}\text { Rate Constant } \\
\min ^{-1} \times 10^{2} \\
\end{array}$ & $\begin{array}{c}\text { Energy of } \\
\text { activation, } \mathrm{kJ} \mathrm{mol}^{-1}\end{array}$ & $\begin{array}{c}\text { Enthalpy } \\
\text { change kJ mol }^{-1}\end{array}$ & $\begin{array}{c}\text { Entropy, } \\
\mathrm{kJ} \mathrm{K}^{-1} \mathrm{~mol}^{-1} \times 10^{2} \\
\end{array}$ \\
\hline 303 & 11.56 & \multirow{4}{*}{$9.11 \pm 0.04$} & \multirow{4}{*}{$17.72 \pm 0.04$} & \multirow{4}{*}{$8.64 \pm 0.03$} \\
\hline 313 & 12.34 & & & \\
\hline 323 & 12.97 & & & \\
\hline 333 & 14.13 & & & \\
\hline
\end{tabular}

Table 2. Thermodynamic parameter for adsorption of $\mathrm{Eu}(\mathrm{III})$ ions on local clay

\begin{tabular}{ccccc}
\hline $\begin{array}{c}\text { Temperature, } \\
\mathrm{K}\end{array}$ & $\begin{array}{c}\text { Rate Constant } \\
\mathrm{min}^{-1} \times 10^{2}\end{array}$ & $\begin{array}{c}\text { Energy of } \\
\text { activation, } \mathrm{kJ} \mathrm{mol}^{-1}\end{array}$ & $\begin{array}{c}\text { Enthalpy } \\
\text { change, } \mathrm{kJ} \mathrm{mol}^{-1}\end{array}$ & $\begin{array}{c}\text { Entropy, } \\
\mathrm{kJ} \mathrm{K}^{-1} \mathrm{~mol}^{-1} \times 10^{2}\end{array}$ \\
\hline 303 & 9.46 & & & \\
313 & 10.24 & $10.46 \pm 0.08$ & $10.06 \pm 0.03$ & $7.46 \pm 0.04$ \\
323 & 10.87 & & & \\
333 & 12.03 & & & \\
\hline
\end{tabular}

The Arrhenius plots of $\log k_{1} v s .1 / T$ gave the activation energies for the adsorption process of $\mathrm{Ce}(\mathrm{III})$ on clay as $9.11 \pm 0.04$ and on Eu on clay as $10.46 \pm 0.08 \mathrm{kJmol}^{-1}$. These low values of activation energies for both the systems indicates that the process of uptake can occur even under normal conditions of temperature and pressure and also indicate about the strong force of attraction operating during the adsorption. The change in standard enthalpy $\Delta H^{0}$ during the adsorption process has been evaluated using Van't Hoff equation (3);

$$
\log K_{\mathrm{D}}=\frac{\Delta \mathrm{H}^{0}}{2.303 R T}+\text { Constant }
$$

Where $K_{\mathrm{D}}, \Delta H^{0} R$ and $T$ have their usual meaning. The values of $\Delta H^{0}$ (at $303 \mathrm{~K}$ ) found from the slopes of straight lines obtained by plotting $\log K_{\mathrm{D}} v s .1 / T$ are found to be 17.72 $\pm 0.04 \mathrm{kJmol}^{-1}$ for Ce-Clay and $10.06 \pm 0.03 \mathrm{kJmol}^{-1}$ for Eu-Clay systems respectively. The positive value of $\Delta H^{0}$ confirms the endothermic nature of the adsorption process ${ }^{22}$ and the numerical value indicates an ion exchange type mechanism ${ }^{23}$ for the uptake.

\section{Desorption study}

Clay with preadsorbed $\mathrm{Ce}(\mathrm{III})$ and $\mathrm{Eu}(\mathrm{III})$ was washed with double distilled water to ensure the removal of adhering species and subsequently the adsorbent was dried in an electric oven at $383 \mathrm{~K}$. The desorption of preadsorbed ions on these solid was studied in $\mathrm{Ce}(\mathrm{III})$ and $\mathrm{Eu}$ (III) solution $\left(1.0 \times 10^{-5} \mathrm{~mol} \mathrm{dm}^{-3}\right)$ at different temperatures (i.e., 303 to $\left.333 \mathrm{~K}\right)$. The very low values of percentage desorption at different temperatures ( $c f$ Table 3 ) indicates that the desorption process is almost independent of temperature. Thus a low value of desorption, unaffected by increase of temperature shows that the process of adsorption for ions is irreversible in nature. It also indicates that a major part of ion were probably bound to the clay surface through strong interaction and converted to a final stable adsorption phase. 
Table 3. Effect of time on the desorption of Cerium and Europium using $0.01 \mathrm{~mol} \mathrm{dm}^{-3}$ $\mathrm{CaCl}_{2}$ and water as desorbent

\begin{tabular}{cccc}
\hline Fission Product & $\begin{array}{c}\text { Time of } \\
\text { Desorption, } \mathrm{h}\end{array}$ & $\begin{array}{c}\text { \% Desorption } 0.01 \mathrm{~mol} \mathrm{dm}^{-3} \\
\mathrm{CaCl}_{2} \text { Plain Water }\end{array}$ \\
\hline \multirow{3}{*}{$\mathrm{Ce}$} & 1 & 1.04 & 0.51 \\
& 4 & 1.09 & 0.33 \\
& 24 & 1.11 & 0.46 \\
$\mathrm{Eu}$ & 1 & 0.57 & 0.42 \\
& 4 & 0.76 & 0.31 \\
& 24 & 0.82 & 0.30 \\
\hline
\end{tabular}

\section{Effect of $p H$}

In order to find out the mechanism involved at the solid/solution interface, the study has been extended for the adsorption of ions on the surface clay as a function of adsorptive $\mathrm{pH}$ at a constant temperature $(303 \mathrm{~K})$ and using metal ion solution of $1.0 \times 10^{-5} \mathrm{~mol} \mathrm{dm}$. Cerium(III) and Europium(III) occurs with its stable +3 oxidation state and exists with its various forms on varying the $\mathrm{pH}$ range 2-9 of solution (Figure 4). The sorption increased with $\mathrm{pH}$ in the both cases with relatively greater effect on $\mathrm{Eu}(\mathrm{III})$. Above $\mathrm{pH} 7$ the uptake of the cations was almost complete. At lower $\mathrm{pH}$ lesser adsorption was due to completion of hydrogen ions with $\mathrm{Eu}(\mathrm{III})$ and $\mathrm{Ce}(\mathrm{III})$ for exchange sites. At higher $\mathrm{pH}$ hydrolyzed species are formed and are precipitated as hydroxides.

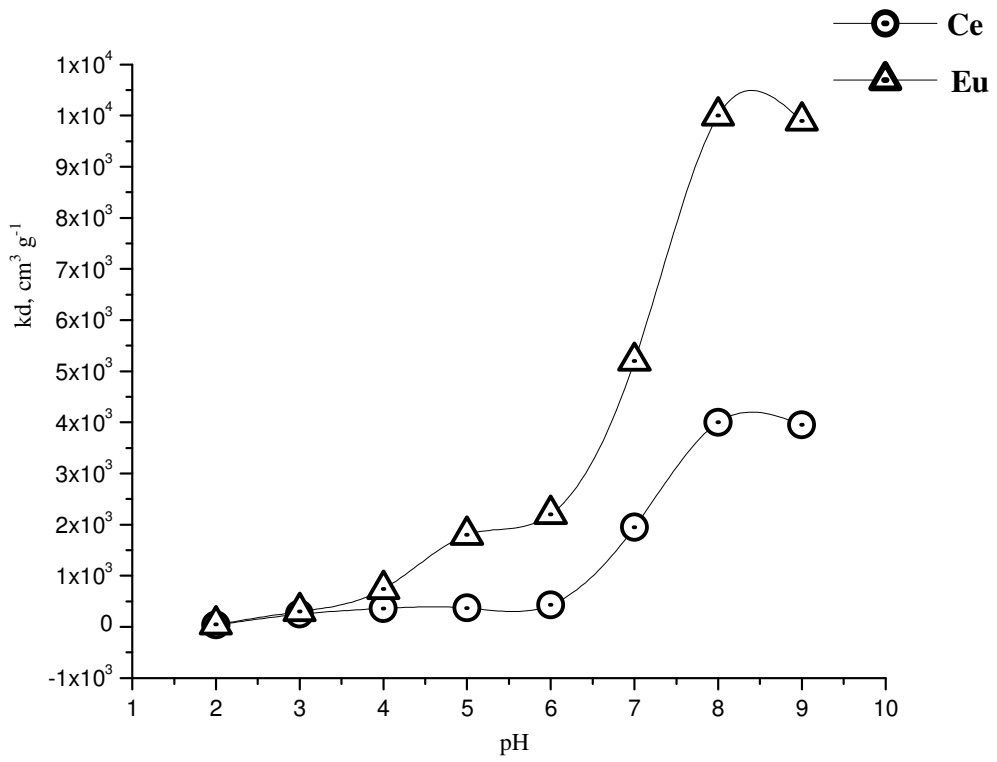

Figure 4. Effect of $\mathrm{pH}$ on the sorption of $\mathrm{Ce}$ and $\mathrm{Eu}$

\section{Conclusion}

Clay was found to be effective in rapid and efficient removal of micro concentrations of $\mathrm{Ce}$ (III) and $\mathrm{Eu}(\mathrm{III})$ toxic ions from aqueous solutions. The adsorption process follows Freundlich isotherm with endothermic/irreversible nature. 


\section{Acknowledgment}

I wish to thank the Head of Department of Chemistry, BHU, Varanasi, for providing necessary facilities

\section{References}

1. Beneã P, Štamberg K, Široký L and Mizera J, J Radioanal Nucl Chem., 2002, 254(2), 231-239.

2. Mizera J, Mizerová G and Bene P, J Radioanal Nucl Chem., 2005, 263(1), 75-80.

3. Mishra S P and Vijaya, J Radioanal Nucl Chem., 2007, 274(2), 265-269.

4. Sandip R S, Jadhav D V and Mohite B S, J Radioanal Nucl Chem., 2010, 284, 273-278.

5. Ambe S, Langmuir, 1987, 3(4), 489-493.

6. Bhattacharya D K, Dutta N C and De A, J Radioanl Nucl Chem., 1990, 140, 121-129.

7. Mikhail E M and Misak N Z, Int J Appl Radiat Isot., 1988, 39, 1121-1128.

8. Tewari P N, Adsorption from Aqueous Solutions, 1981, Plenum, New York.

9. $\quad$ Gill J S and Tandon S N, Radiochem Radioanal Lett., 1973, 14, 379-386.

10. Zsinka L, Szirtes L, Mink J and Kalman A, J Inorg Nucl Chem., 1974, 36, 1147-1157.

11. Mathew J, Tandon S N and Gill J S, Radiochem Radioanal Lett., 1977, 30, 381-392.

12. Ahmed S and Qureshi I H, J Radioanal Nucl Chem., 1989, 130(2), 347-352.

13. Del Debbio J A Radiochem Acta, 1991, 52/53, 181-186.

14. Barrow N J and Cox V C, J Soil Sci., 1992, 43, 305-313.

15. Kocjan R, Analyst, 1992, 117, 741-751.

16. Dubey S S and Rao B S, J Hazad Mater., 2011, 186(2-3), 1028-1032.

17. Ma X, Subramanian K S, Chakrabarti C L, Guo R, Cheng J, Lu Y and Pickring W F, J Environ Sci Health, Part A, 1992, 27, 1389-1397.

18. Flaschka H, An Introduction to Theory and Practice, $2^{\text {nd }}$ Ed. Pergamon Press Oxford 1964.

19. Gupta R K, Dubey S S and Singh R A, Separ Purif Tech., 2004, 38(3), 225-232.

20. Mishra S P, Dudey S S and Tiwari D, J Radioanal Nucl Chem., 2004, 261(2), 457-463.

21. Gupta R K and Shankar S, Adsorption Science and Technology, 2004, 22(6), 485-496.

22. Mishra S P, Dubey S S and Tiwari D, J Colloid and Interface Sci., 2004, 279, 61-67.

23. Helfferich F, Ion-Exchange, McGraw Hill, New York, 1962, 116-124. 


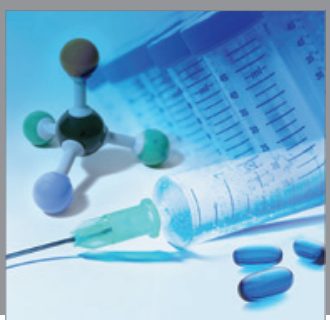

International Journal of

Medicinal Chemistry

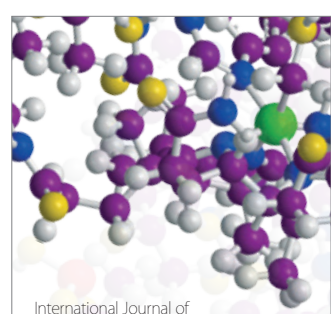

Carbohydrate Chemistry

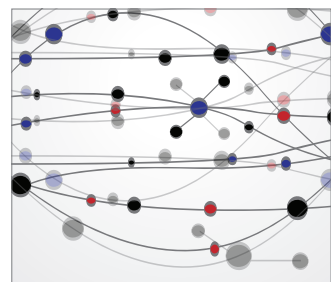

The Scientific World Journal
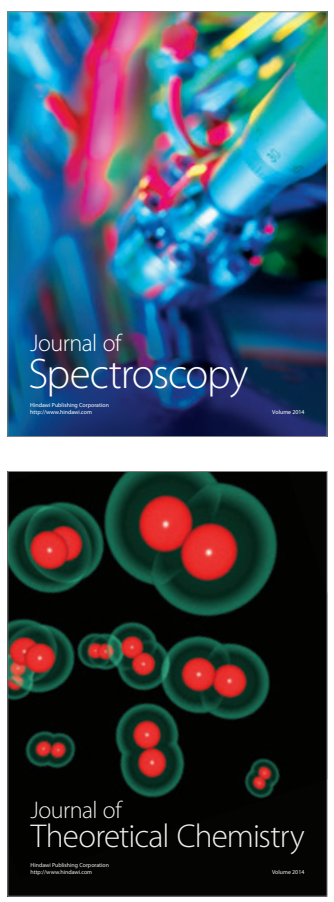
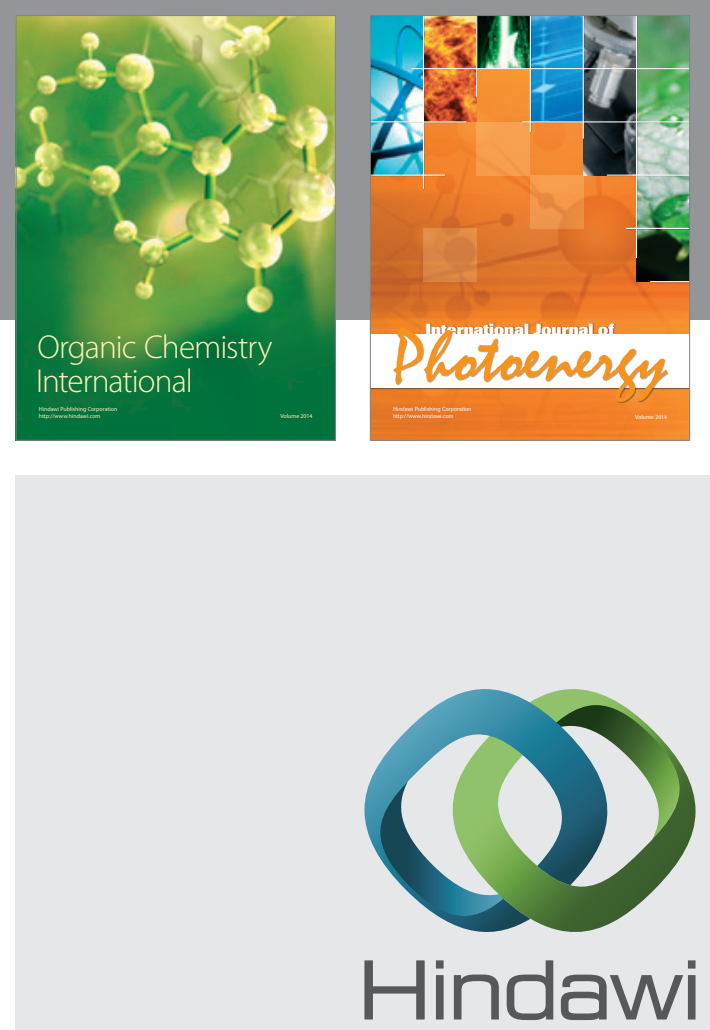

Submit your manuscripts at

http://www.hindawi.com
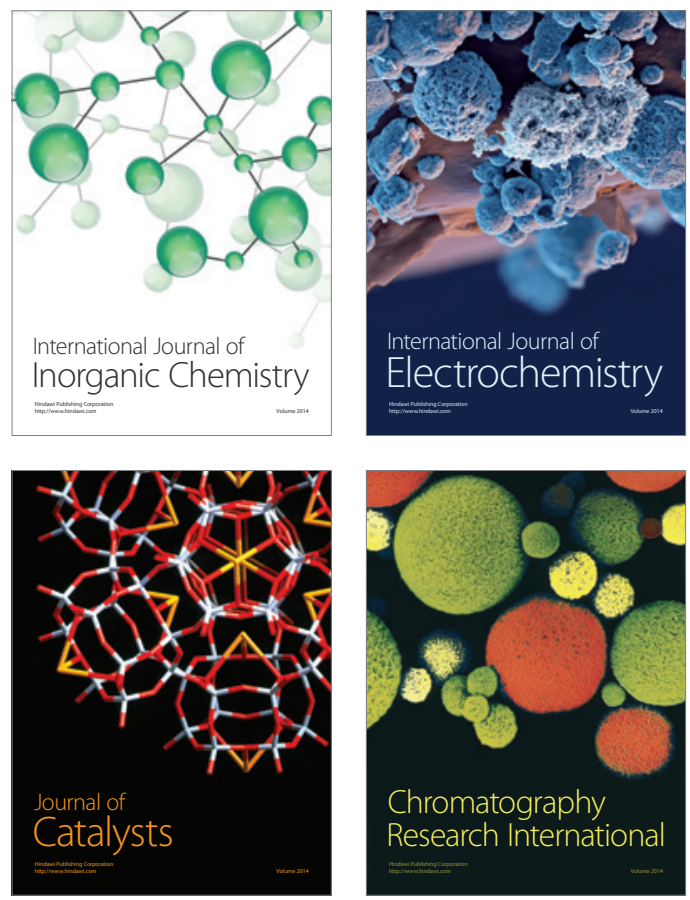
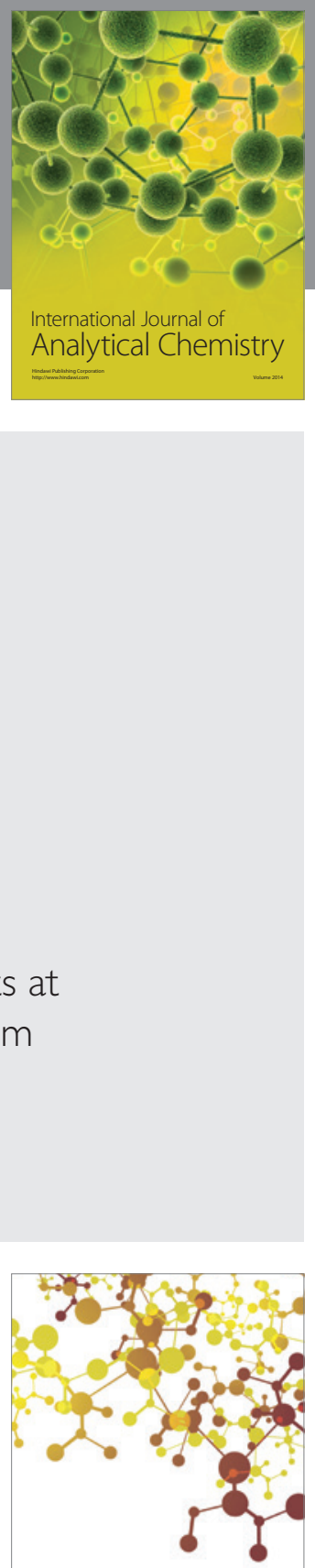

Journal of

Applied Chemistry
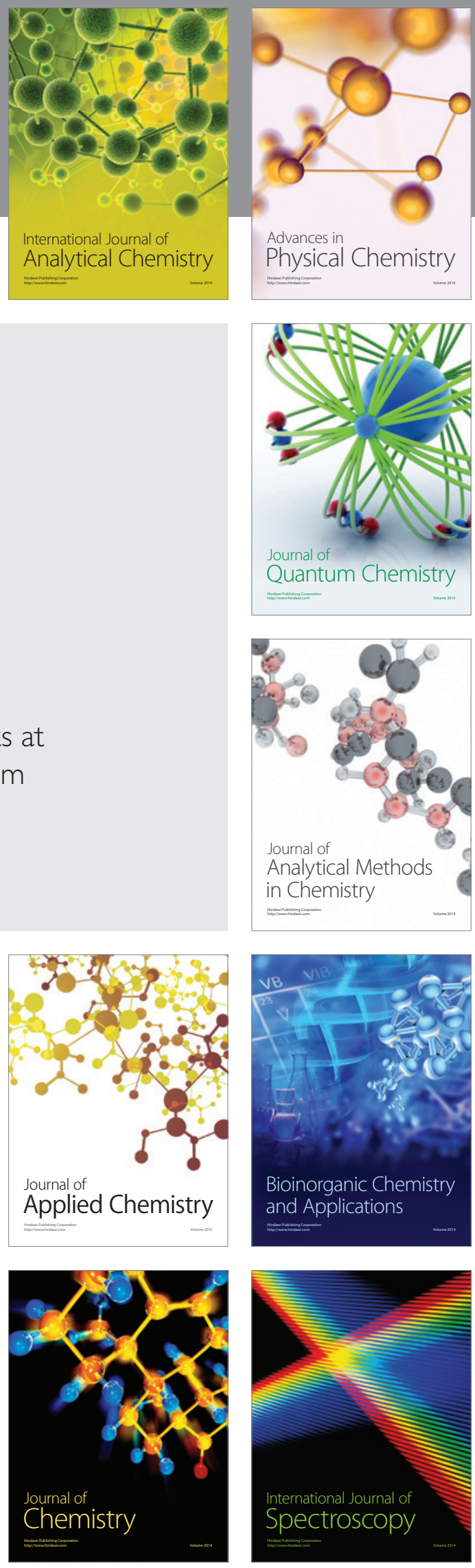